\title{
Emergency admissions and subsequent inpatient care through an emergency oncology service at a tertiary cancer centre: service users' experiences and views
}

Hong Chen, Miriam Johnson, Elaine Boland, Julie Seymour, Una Macleod

\section{Hong Chen (Corresponding author)}

Institute of Clinical and Applied Heath Research

3rd Floor, The Allam Medical Building

University of Hull

Cottingham Road

Hull, HU6 7RX

Hong.Chen@hyms.ac.uk

$+44(0) 1482463124$

ORCID 0000-0002-5102-6302

\section{Miriam Johnson}

Institute of Clinical and Applied Heath Research

3rd Floor, The Allam Medical Building

University of Hull

Cottingham Road

Hull, HU6 7RX

\section{Elaine Boland}

Queen's Centre for Oncology and Haematology

Hull and East Yorkshire Hospitals NHS Trust

Castle Hill Hospital

Castle Road

Cottingham, HU16 5JQ

\section{$\underline{\text { Julie Seymour }}$}

Institute of Clinical and Applied Heath Research

3rd Floor, The Allam Medical Building

University of Hull 
Cottingham Road

Hull, HU6 7RX

Una Macleod

Institute of Clinical and Applied Heath Research

3rd Floor, The Allam Medical Building

University of Hull

Cottingham Road

Hull, HU6 7RX 


\begin{abstract}
Purpose Avoiding unnecessary emergency admissions and managing those that are admitted more effectively is a major concern for both patients and health services. To generate evidence useful for improving services for direct patient benefit, this study explores service users’ views and experiences of emergency admissions and subsequent inpatient care.
\end{abstract}

Methods Participants were recruited during a cancer-related emergency admission from a tertiary cancer centre with an emergency oncology service and emergency department. Semi-structured interviews were conducted with fifteen patients and twelve carers post hospital discharge. Interview transcripts were analyzed using framework analysis.

Results Twenty patients experienced 43 emergency admissions over six months. Most admissions (35/43) followed patients presenting acutely or as emergencies with cancer treatment side-effects. Most admissions (35/43) were directly to an oncology ward following specialist advice, review and triage and thus unavoidable. Participants experienced outstanding inpatient care because of: prompt and effective symptom control and stabilization of acute conditions; continuity of cancer care and coordination between acute and long-term treatment; satisfactory professional-patient communication and information sharing; responsive, motivated and competent staff; and less restrictive visiting times. Gaps in care were identified.

Conclusions Many emergency admissions are necessary for people with cancer. Future work should focus on: improving easy access to specialist advice and triage, and the process of admission; providing rapid palliation of symptoms and prompt stabilization of acute conditions, and satisfactory inpatient care; closing the circle of care for patients by actively involving primary care and palliative/end-of-life care services to address the complex needs of patients and carers.

Keywords Cancer. Outpatient. Side effect. Emergency admission. Inpatient care. Users’ experience 


\section{Background}

The number of emergency admissions, i.e. those that are not planned and happen at short notice because of perceived clinical need, continues to rise (a 47\% increase over the last 15 years in the UK) at a time when health service budgets are under significant pressure [1-3]. Emergency admissions can result from suboptimal care and represent threats to patient safety such as preventable adverse drug events, healthcare associated infections, procedural complications, and avoidable exacerbations in disease states or functional declines [4-6]. Avoiding unnecessary emergency admissions and managing those that are admitted more effectively is therefore a major concern: not only because of the costs associated with these admissions, but also because of the pressure and disruption they can cause to elective healthcare and, not least, to the individuals admitted [1, 7].

Cancer is no exception: the number of emergency admissions among people with cancer has been steadily increasing in the UK [8]. While the total inpatient bed-days used by people with cancer has fallen, emergency admissions linked to cancer doubled (2000-2009). This trend has been often attributed to factors such as suboptimal primary and community care, inappropriate aggressiveness of cancer treatment (especially in the last phase of life) and an inadequate territorial coverage by palliative care services, hence the assumption that a significant number of emergency admissions are unnecessary and avoidable [1, 6, 9-11]. However, there is growing evidence that the request of hospital admission and of acute care is somewhat unavoidable in the cancer trajectory: cancer patients have unpredictable and complex medical needs that in many instances can be managed only in the context of inpatient services [12-17].

For people with cancer, active treatments are offered throughout the majority of the disease course with more treatments being delivered in the outpatient setting [15, 18-21]. Patients therefore need to manage their own care and treatment-effects between planned visits [18] while they are burdened by overlapping treatmentrelated toxicities, disease-induced symptoms and psychological issues [19]. With high levels of physical and psychological suffering and unmet needs [15, 20, 22-24], cancer outpatients tend to consume healthcare resources additional to their routine visits- often emergency presentations and admissions due to acute cancerrelated conditions [12-15, 23-27]. Consequently, urgent admission through an emergency department (ED) is common among cancer patients $[11,13,14,16,17,27,28]$; and the oncology wards, once intended to deliver complex active treatments, are now frequently used for symptom management and for terminal care [12, 13, $20]$.

With the growing clinical challenge of acutely ill cancer patients, various models of emergency and acute cancer care are developing in the USA and UK [29]. In the USA, two tertiary cancer centres have 
developed an ED and urgent care centre, respectively, solely for the acute care of their patients. In the UK, there are two strategies for delivering "emergency oncology" services: specialist admission units in tertiary cancer units and acute oncology services to support patients admitted to non-cancer hospitals. The importance of these emerging specialist emergency care services is the fact that they signify a recognized need for specialized care of these patients. Limited initial research evidence also suggested that these services may reduce (re)admission rates and length of hospital stay, and deliver significant cost savings. However, there are only a few centres worldwide that provide specialized unscheduled, urgent care for cancer patients, and thus only a small percentage of cancer patients receive such care. To date, there is little research into the impact of these services on patient care and patient experience, particularly from service users' perspective. This study explores patients' and carers' experiences of and views on cancer-related emergency admissions and subsequent inpatient carethrough a specialist admission unit in a tertiary cancer care centre.

\section{Methods}

This qualitative study employs semi-structured interviewing to collect data from cancer patients and their carers. Ethics approval was given, including for the method of identification and consent by the National Research Ethics Service in October 2015 (Ref: 15/NW/0865) prior to recruitment.

\section{Setting and sample}

The Hull and East Yorkshire NHS Trust operates from two main sites, with its tertiary cancer care centre being at one site and the major ED at the other site. The cancer centre operates an emergency oncology service to triage and manage unplanned presentations and admissions for acutely ill cancer patients. All patients receiving cancer treatment have 24-hour, 7-day access to a specialist helpline run by nurse specialists who carry out telephone assessment and triage of patients based on the UK Oncology Nursing Society (UKONS) guidelines [30]. If patients are triaged as having a condition related to the cancer or its treatment, they can be admitted to the four oncology wards in the centre (99 beds) when necessary. Locally, the majority of emergency admissions in cancer patients are directly to the oncology wards through this service.

Patients were recruited from the cancer centre and the ED. A purposive-sampling strategy was adopted [31]: we aimed for maximum variation with respect to patients' sociodemographic background and clinical outcomes. Eligible participants were: 1) consenting adults with a cancer diagnosis and active disease; 2) aware 
of the cancer diagnosis; 3) undergoing an unplanned admission related to cancer; and 4) well enough to be interviewed. Patient participants were asked to nominate a carer who had been involved in the emergency admission(s), and permission asked to invite them to participate.

A research nurse screened the (electronic or paper-based) emergency admission lists regularly to identify eligible patients, and approached them and their carers during the emergency admission about the study. She obtained their verbal consent for participation and for passing their contact details onto the researcher $\left(1^{\text {st }}\right.$ author) before patients were discharged. The researcher then contacted patients and carers post hospital discharge to arrange an interview.

\section{Data collection}

Twenty semi-structured interviews were conducted by 1st author between May and December 2016.

Participants were interviewed at a place and time suitable to them, usually within 4 weeks of discharge. Seven patients had a carer available for interview; these patients and their carers were offered the opportunity to be interviewed individually, but all opted for a conjoint interview. Eight patients were interviewed alone - with no carer available. In five cases, only carers were interviewed because patients were extremely ill or unable to talk. Interviews lasted 50 minutes on average.

To explore "patient complexity" (p. 1041) in emergency admissions, the interview topic guide was based on a patient-centred conceptual framework- The Cumulative Complexity Model [32]. It emphasizes patients' workload - capacity balance and incorporates treatment and illness burdens in understanding "a dynamic state in which the personal, social, and clinical aspects of the patient's experience operate as complicating factors” (p. 1041) which interact with each other to affect a patient's care and outcomes.

During the interview, participants were encouraged to describe in detail their most recent admission: the events immediately prior to admission, the admission itself, inpatient care post admission and the outcome(s) of the admission. They were asked to reflect on factors that might have contributed to the admission (personal, social and clinical) and what could have been done differently to avoid it. Those who had more than one admission over the last 6 months were also asked to describe in detail earlier admissions. Data saturation was reached after 20 interviews (describing 43 admissions) - no new ideas emerged and recurrent themes became established [33].

\section{Data Analysis}


Interviews were transcribed verbatim and rendered anonymous through the use of pseudonyms and removal of distinguishing features. Interview transcripts were analyzed using framework analysis [34, 35], with the aid of NVivo11. Following a well-defined procedure, framework analysis made it possible to reconsider and rework ideas because the analytical process had been documented. This facilitated team work in analysis and thus strengthened validity. The analysis was grounded in data, informed by concepts or issues emerging from the data, and a priori issues - those introduced into the interviews as informed by the research questions. An analytical framework (matrix) was developed that was both case and theme based. Two types of cases were used: a patient as a case and an admission episode as a sub-case. Summarized data were entered into the matrix (a spreadsheet), which provided an intuitively structured overview of the data while situating each perspective in context by retaining the connection to other aspects of each individual's account. Analytical comparison was then made both within and across cases. Patterns and connections were searched for and explanations sought for these internally within the data.

\section{Results}

\section{Characteristics of admissions}

Twenty patients, most (17) living with advanced cancer, had 43 emergency admissions over six months- more than half (13) had 2-4 admissions (Table 1). All patients experienced severe symptoms prior to the admissions; ten most common symptoms were listed in Table 2. In most admissions (35/43), symptoms were related to treatment- chemotherapy (30), radiotherapy (2) or immunotherapy (3). Most admissions (38/43) were to an oncology ward- directly (35) or indirectly via ED (3) (see Table 2 and Figure 1). In 31 admissions, patients were directly admitted to an oncology ward by their specialist teams: 26 admissions arranged by a nurse specialist following patients/carers contacting the centre; 5 admissions made by a consultant (or registrar) as the result of routine monitoring. Depending on symptom severity and urgency, the process of admission varied: it was straightforward in most cases (35/43) involving only one transfer (mostly home to oncology ward), and was only convoluted in a few cases (see Figure 1). Most admissions (39/43) resulted in a short hospital stay between 2 days and a week; during which investigations and management of the symptoms were performed.

\section{Avoidable admission or not}


Self-management preceded seeking professional help in most cases, including taking prescribed medications, resting and watchful waiting. Self-management lasted for hours to days until symptoms became "unbearable” or “out of control”, or developed into emergency situations, or were detected by tests (Table 3: Q1). For a few, symptom onset was so quick and severe that it triggered the immediate response of carers to call emergency service (999); for example, when patients had stroke-like or heart-attack-like symptoms, or “collapsed” or “passed out” (Table 3: Q2). As such, the admissions were a last resort to patients and carers.

All patients were known to the hospital specialist teams. Nineteen patients were undergoing chemotherapy as an outpatient; three had radiotherapy or immunotherapy (on its own or additional to chemotherapy). They were all routinely monitored by their oncologists (Table 3: Q3). Five admissions resulted from and were arranged during a routine appointment (Figure 1).

In addition, patients had 24-hour, 7-day access to the centre, using specific day or out-of-hours numbers (Table 3: Q4). They were told to contact the centre as needed. Most patients had contacted the centre for help and advice during cancer treatment, praising the centre for the good service they received. When patients/carers rang the centre, depending on the nature and severity of the symptoms, a nurse specialist had: given advice on how to monitor/improve symptoms at home; asked patients to go to the centre to be assessed and treated during the day; directly arranged for patients to be admitted to an oncology ward; or suggested that carers/patients contact other services for help (Table 3: Q5 and Q6). Most admissions (30/43) resulted from such a triage process and were considered necessary (Figure 1). General practitioners (GPs) and other community health professionals could also contact the centre to arrange for a patient to be admitted. For example, two admissions were arranged with the centre by the GP monitoring the patient (Figure 1).

In most cases, patients and carers thought that the admission was inevitable (Table 3: Q7). They gave the following reasons: 1) it was lifesaving; 2) professional guided self-management at home failed; 3) further investigations were deemed by professionals as necessary; 4) patients needed medical treatment that could not have been provided at home; or 5) it was part of the treatment- as long as they had chemotherapy, they needed hospital care to deal with its side effects. Only in very few cases, participants thought that the admission could have been avoided, for example, if professionals in the community had responded better, or if patients had taken the prescribed medications in time.

\section{Inpatient care post admission}


In most cases, patients were admitted to an oncology ward (Figure 1) where most received outstanding inpatient care. They described the oncology wards “a nice place to be”, i.e. a generally caring, relaxing, welcoming and comfortable place. This was mainly attributed to the staff including doctors, nurses, volunteers, cleaners and so on. They were frequently praised by patients and carers using phrases such as "absolutely beautiful" or "top class” because they found them "very supportive”, "happy and smiley”, "very patient”, "very attentive”, "most caring" and "most professional". As a result, most patients and carers felt that their needs were met satisfactorily and they were well looked after (Table 3: Q8).

Some specific aspects of inpatient care were particularly appreciated. Clinically, patients reported that they were seen, assessed and treated promptly; and that their symptoms were well controlled by the time they were discharged. The acute inpatient care did not interrupt patients' long-term treatment; for example, the wards were flexible in medication taking times; so patients were able to adhere to their medication regimens (for cancer and other health problems) without disruption (Table 3: Q9). Also, continuity of care was maintained, i.e. patients were treated by their "usual care” team who knew about them (Table3: Q10).

In addition, participants felt that they could talk to the staff, were listened to and taken seriously. They felt well informed- they knew as much as they would like to know about the disease, treatment and care arrangement. Their requests and needs were responded to promptly. Generally, the staff appeared to have a cando attitude and have done their best to help patients and carers (Table 3: Q11). The wards were less restrictive in visiting times (e.g. 1.30pm - 8.00pm); it was more convenient for visitors; and patients felt they got enough company (Table 3: Q12).

In contrast, a few patients who had been admitted to other wards via ED complained about longer waiting times, restricted medication times disrupting their long-term treatment regimen, restricted visiting times, and generally unsatisfactory levels of care resulting in unmet needs.

\section{Care at home}

To various extents, all patients relied on family members to cope with cancer at home. Most of them needed significant hands-on care, unable to perform many or all daily activities independently. Most therefore had a dedicated or full-time family carer- very often a spouse or a partner, occasionally daughter(s) (Table 1). While caring for the patient, some carers were coping with their own health problems and disabilities (Table 3: Q13). Some were juggling many demands- work, care for the patient and for other dependent family members (e.g. 
children, spouse, grandchildren or pets) (Table 3: Q14). Carer strain and burden was therefore common although they were not considered by the participants to have contributed to patients' admissions.

In terms of medical and nursing care from community-based professionals, patients and carers reported only occasionally receiving such care at home during cancer treatment. It was often arranged ad hoc; for example, district nurses visited patients to take bloods, change dressings, give injections or treat wounds. Patients could still use their GP services but did not feel a need to do so due to routine hospital visits. It seemed that only when the cancer progressed to a very advanced or terminal stage and cancer treatment was no longer given did patients receive at home on a regular basis medical and nursing care from community palliative care nurse specialists, GPs and district nurses (Table 3: Q15).

\section{Discussion}

This study has generated new findings regarding the experience of people with cancer-related emergency admissions through an emergency oncology service in a tertiary cancer centre: reasons for and process of admissions including prior access to specialist advice and triage, contributing factors to good inpatient care, and gaps in community-based care.

Almost all admissions (42/43) in this study were for symptom relief, following patients presenting acutely or as emergencies with cancer treatment side-effects (35) or complications from a known cancer diagnosis (7). This supports the previous evidence that cancer outpatients frequently need hospital admission in acute care settings resulting from high symptom burden [12-14, 17, 20]- very often related to chemotherapy [15, 19, 22-25]. Furthermore, most admissions were deemed unavoidable by cancer specialists, resulting from the nurse specialist- led triage process (30/43) or from routine monitoring by oncologists (5/43); and were also perceived as a last resort by patients and carers. As such, emergency admissions may be a necessary step in the cancer trajectory because outpatients can have unpredictable and complex medical needs that sometimes can only be met in an inpatient setting [12-15, 17, 19, 19, 20, 22-25]. Under such circumstances, more attention should be given to improving: monitoring with provision of easily accessible and specialist advice, the admission processes and inpatient care afterwards.

Previous studies show that cancer patients needing emergency admission came into hospital mostly via ED $[12,14,15,17,27,28,36]$. Such admissions and subsequent inpatient care may be distressing for patients and carers because of: long waiting times, multiple referrals and thus transfers (between units or wards), clinical 
assessment provided by physicians who do not usually care for the patient, partial patient knowledge affecting clinical decision making and risking inappropriate and possibly futile interventions, lack of attention to patients’ fundamental needs, poor communication about care plans, and generally lower levels of care [12, 13, 36]. In contrast, most admissions (35/43) in this study were directly to an oncology ward involving one transfer (home to ward), and thus more straightforward and less taxing to patients and carers. A similar study also found that patients favoured admission to an oncology ward directly [12]. Moreover, those admitted to an oncology ward experienced outstanding inpatient care attributable to: 1) prompt and effective symptom control and stabilization of acute conditions; 2) continuity of cancer care and coordination between acute and long-term treatment regimens; 3) satisfactory professional-patient communication and information sharing; 4) responsive, motivated and competent staff; and 5) adequate visiting times. This study adds to the limited evidence regarding what contributes to a good patient experience when emergency admission is inevitable [12, 37].

Most patients in this study had advanced cancer, some were admitted repeatedly and many needed significant hands-on care by dedicated family carers. Patients with advanced cancer have reduced quality of life, which worsens towards the end of life [38]. Rocque [20] found in her study that an emergency admission for someone with advanced cancer strongly predicts a poor prognosis regardless of cancer type. This is because patients with good performance status who have changes in symptoms often can be managed as outpatients, whereas patients with global decline require admission. Hence, emergency admission may represent an opportunity to commence and/or consolidate appropriate palliative and end-of-life care. In this study setting, the cancer centre has an on-site specialist palliative care consultation team; and it provides inpatient palliative care consultation across the hospitals of the local NHS Trust, working alongside other clinical teams to care for patients wherever they are in the hospitals. Therefore, cancer patients admitted to the oncology wards also benefit from integrated oncology and palliative care during their hospital stay. However, in the community, patients reported only receiving on a regular basis palliative care when the cancer progressed to a very advanced or terminal stage and cancer treatment was no longer given. This indicates a need to increase level of palliative care at an earlier stage of cancer in the community setting.

It is often believed that emergency admissions could be reduced by providing better primary care in the community [1, 9, 39]. However, in cancer care, although some guidelines make specific reference to primary care, in many cases no formal role is described for the primary care practitioners during the treatment or survivorship phases [40]. Some studies show that GPs' role in cancer care fluctuated between active advocacy 
during diagnosis and palliation, and ambivalent redundancy in between [41-43]. Patients and carers in this study also reported only occasionally receiving care from district nurses and GPs when still receiving cancer therapies. Thus, the care of patients, even those with advanced cancer, is being managed by their oncologist.

Patients may prefer their specialists and feel secure under their care, perceiving that they have the necessary knowledge and expertise in cancer care [12, 41, 42]. However, cancer and its treatment can have a wide range of adverse effects- physical, psychological, social and financial, on both the patients and their families [40]. For example, in our study, those dedicated and full-time carers experienced physical and mental health problems while looking after patients and thus had significant unmet needs. As such, patients may also value continuing care by their GPs and perceive that they have an important role in liaising with their specialist, providing information and maintaining routine healthcare including supportive care for themselves and their family [41].

Nonetheless, the involvement of primary care practitioners in the care of patients or carers is unlikely when continuity of care between secondary and primary care is lost during cancer treatment [15]. The fragmented nature of the health-care system can make the engagement of primary care in the management of patients with cancer an operational challenge [40]. Specialists may need to be more active in engaging with primary care practitioners to develop systems where primary and secondary care services are effectively integrated to achieve a common set of goals [1, 9, 15, 42, 44]. Oncologists can promote continued involvement of GPs throughout the cancer trajectory by regular communication about their mutual patients and by encouraging patients to maintain contact with their GPs [41]. Through such coordination of care, oncology providers can ensure that patients' general needs are met and co-morbid conditions well-managed [18].

\section{Limitations}

We were unable to interview some of the patients identified because they were too ill and no carer was available to be interviewed, or they had died before they could be approached. As such, the findings of this study may not represent the experiences of those who were sicker or approaching the end of life. We were also unable to recruit equal numbers of patients admitted directly to the oncology wards and through ED. Locally, only a small percentage of cancer patients are admitted through ED; and therefore it was not attainable to recruit more patients from ED within the time constraints. This study was conducted in a particular (regional) social/health 
system context, and thus the findings are not generalizable directly to other settings - due to variations in the population characteristics, health system procedures and protocols in other contexts of medical care.

\section{Conclusions}

Cancer outpatients, particularly those on chemotherapy, can become acutely ill, with acute conditions and uncontrolled symptoms that need inpatient care. Emergency admissions may be necessary. The drive to reduce admissions should not detract from a focus on the need to improve easy access to timely advice and specialist review, and the process of admission; and to provide rapid palliation of symptoms and prompt stabilization of acute conditions, and good inpatient care. There is also need to close the circle of care for cancer patients by actively involving primary care practitioners and palliative/end-of-life care specialists to address the complex needs of patients and their carers through coordinated care.

Acknowledgements This work was supported by a University of Hull Endowment award from Yorkshire Cancer Research (Ref: HEND001). We are grateful to patients and their carers for their participation during a difficult time. We thank Thomas Hammond for his admin support and Sarah Smith for participant recruitment.

Competing interests The authors declare that they have no competing interests.

Ethical approval All procedures performed in this study were in accordance with the ethical standards of the institutional and national research committee and with the 1964 Helsinki declaration and its later amendments or comparable ethical standards.

Informed consent Informed consent was obtained from all individual participants included in the study. 


\section{References}

1. National Audit Office (2013) Emergency admissions to hospital: Managing the demand. TSO (The Stationery Office), London.

2. Blunt I, Bardsley M, Dixon J (2010) Trends in emergency admissions in England 2004-2009. The Nuffield Trust, London.

3. Blunt I, Bardsley M, Grove A, Clarke A (2014) Classifying emergency 30-day readmissions in England using routine hospital data 2004-2010: What is the scope for reduction?. Emergency Medicine Journal 32:44-50.

4. Donzé J, Lipsitz S, Bates DW, Schnipper JL (2013) Causes and patterns of readmissions in patients with common comorbidities: Retrospective cohort study. BMJ 347:f7171. doi: 10.1136/bmj.f7171.

5. The NHS Confederation (2011) Briefing 211: The impact of non-payment for acute readmissions. The NHS Confederation, London.

6. Tian Y, Dixon A, Gao H (2012) Data briefing: Emergency hospital admissions for ambulatory care-sensitive conditions. The King’s Fund, London.

7. Department of Health (2012) The NHS outcomes framework 2013/14. Department of Health, London.

8. National Audit Office (2010) Delivering the cancer reform strategy. National Audit Office, London.

9. Roland M, Abel G (2012) Reducing emergency admissions: Are we on the right track?. BMJ 345:e6017. doi: 10.1136/bmj.e6017.

10. Royal College of Physicians and Royal College of Radiologists. (2012) Cancer patients in crisis:

Responding to urgent needs. Report of a working party. RCP, London.

11. Henson LA, Higginson IJ, Daveson BA et al (2016) "I'll be in a safe place”: A qualitative study of the decisions taken by people with advanced cancer to seek emergency department care. BMJ Supportive \& Palliative Care 6:394. doi: 10.1136/bmjspcare-2016-001204.28.

12. Yates M, Barrett A (2009) Oncological emergency admissions to the Norfolk and Norwich university hospital: An audit of current arrangements and patient satisfaction. Clinical Oncology 21:226-233. doi: //doi.org/10.1016/j.clon.2008.12.006.

13. Numico G, Cristofano A, Mozzicafreddo A et al (2015) Hospital admission of cancer patients: Avoidable practice or necessary care?. PLOS ONE 10:e0120827. doi: 10.1371/journal.pone.0120827.

14. Mayer DK, Travers D, Wyss A, Leak A, Waller A (2011) Why do patients with cancer visit emergency departments? Results of a 2008 population study in North Carolina. JCO 29:2683-2688. 
15. McKenzie H, Hayes L, White K et al (2011) Chemotherapy outpatients’ unplanned presentations to hospital: A retrospective study. Supportive Care in Cancer 19:963-969.

16. Karasouli E, Munday D, Bailey C, Staniszewska S, Hewison A, Griffiths F (2016) Qualitative critical incident study of patients' experiences leading to emergency hospital admission with advanced respiratory illness. BMJ Open 6:e009030. doi: 10.1136/bmjopen-2015-009030.

17. Gott M, Gardiner C, Ingleton C et al (2013) What is the extent of potentially avoidable admissions amongst hospital inpatients with palliative care needs?. BMC Palliative Care 12:9.

18. McCorkle R, Ercolano E, Lazenby M et al (2011) Self-management: Enabling and empowering patients living with cancer as a chronic illness. CA: A Cancer Journal for Clinicians 61:50-62.

19. Aprile G, Pisa FE, Follador A et al (2013) Unplanned presentations of cancer outpatients: A retrospective cohort study. Supportive Care in Cancer 21:397-404.

20. Rocque GB, Barnett AE, Illig LC et al (2013) Inpatient hospitalization of oncology patients: Are we missing an opportunity for end-of-life care?. Journal of Oncology Practice 9:51-54.

21. Teno JM, Gozalo PL, Bynum JPW et al (2013) Change in end-of-life care for Medicare beneficiaries: site of death, place of care, and health care transitions in 2000, 2005, and 2009. JAMA 309:470-477. doi:

10.1001/jama.2012.207624.

22. Mitchell T (2007) The social and emotional toll of chemotherapy - patients’ perspectives. European Journal of Cancer Care 16:39-47. doi: 10.1111/j.1365-2354.2006.00701.x.

23. Hassett MJ, O'Malley AJ, Pakes JR, Newhouse JP, Earle CC (2006) Frequency and cost of chemotherapyrelated serious adverse effects in a population sample of women with breast cancer. JNCI: Journal of the National Cancer Institute 98:1108-1117.

24. Foltran L, Aprile G, Pisa FE et al (2014) Risk of unplanned visits for colorectal cancer outpatients receiving chemotherapy: A case-crossover study. Supportive Care in Cancer 22:2527-2533.

25. Baena-Cañada JM, Estalella-Mendoza S, Rosado-Varela P et al (2012) Use of health-care services during chemotherapy for breast cancer. European Journal of Cancer 48:3328-3334. doi:

//doi.org/10.1016/j.ejca.2012.04.024.

26. Earle CC, Landrum MB, Souza JM, Neville BA, Weeks JC, Ayanian JZ (2008) Aggressiveness of cancer care near the end of life: Is it a quality-of-care issue?. JCO 26:3860-3866.

27. Manzano JM, Luo R, Elting LS, George M, Suarez-Almazor M (2014) Patterns and predictors of unplanned hospitalization in a population-based cohort of elderly patients with GI cancer. JCO 32:3527-3533. 
28. Purdy S (2010) Avoiding hospital admissions: What does the research evidence say? The King’s Fund, London.

29. Cooksley T, Rice T (2017) Emergency oncology: Development, current position and future direction in the USA and UK. Support Care Cancer 25:3-7. doi: 10.1007/s00520-016-3470-1.

30. The UK Oncology Nursing Society (UKONS) (2016) Oncology/haematology 24-hour triage toolkit. UKONS, Marlow.

31. Palys T (2008) Purposive sampling. In: Given LM (ed) The sage encyclopedia of qualitative research methods. (vol.2). Sage, Los Angeles, pp 697-698.

32. Shippee ND, Shah ND, May CR, Mair FS, Montori VM (2012) Cumulative complexity: A functional, patient-centered model of patient complexity can improve research and practice. J Clin Epidemiol 65:10411051.

33. Francis JJ, Johnston M, Robertson C et al (2010) What is adequate sample size? Operationalising data saturation for theory based interview studies. Psychol Health 10:1229-1245.

34. Ritchie J, Spencer L (1994) Qualitative data analysis for applied policy research. In: Bryman A, Burgess RG (eds) Analysing qualitative data. 1st edn. Routledge, London, pp 173-194.

35. Gale NK, Heath G, Cameron E, Rashid S, Redwood S (2013) Using the framework method for the analysis of qualitative data in multi-disciplinary health research. BMC Medical Research Methodology 13:117. doi: 10.1186/1471-2288-13-117.

36. Bailey C, Hewison A, Karasouli E, Staniszewska S, Munday D (2016) Hospital care following emergency admission: A critical incident case study of the experiences of patients with advanced lung cancer and chronic obstructive pulmonary disease. J Clin Nurs 25:2168-2179.

37. Warrington L, Holch P, Kenyon L et al (2016) An audit of acute oncology services: Patient experiences of admission procedures and staff utilisation of a new telephone triage system. Support Care Cancer 24:5041-5048. doi: 10.1007/s00520-016-3370-4.

38. Zimmermann C, Swami N, Krzyzanowska M et al (2014) Early palliative care for patients with advanced cancer: A cluster-randomised controlled trial. The Lancet 383:1721-1730.

39. Burge F, Lawson B, Johnston G (2003) Family physician continuity of care and emergency department use in End-of- Life cancer care. M ed Care 41:992 -1001.

40. Rubin G, Berendsen A, Crawford SM et al (2015) The expanding role of primary care in cancer control. The Lancet Oncology 16:1231-1272. 
41. Halkett GKB, Jiwa M, Lobb EA (2015) Patients' perspectives on the role of their general practitioner after receiving an advanced cancer diagnosis. European Journal of Cancer Care 24:662-672.

42. Mitchell GK, Burridge LH, Colquist SP, Love A (2012) General practitioners' perceptions of their role in cancer care and factors which influence this role. Health \& Social Care in the Community 20:607-616.

43. Beccaro M, Lora Aprile P, Scaccabarozzi G, Cancian M, Costantini M (2013) Survey of Italian general practitioners: Knowledge, opinions, and activities of palliative care. J Pain Symptom Manage 46:335-344.

44. Norman A, Sisler J, Hack T, Harlos M (2001) Family physicians and cancer care. Palliative care patients' perspectives. Can Fam Physician 47:2009-2012. 
Table 1 Patients’ demographic and clinical characteristics $(\mathbf{n}=20)$

\begin{tabular}{|c|c|}
\hline Characteristic & $\mathbf{N}$ \\
\hline \multicolumn{2}{|l|}{ Age } \\
\hline $40-49$ & 1 \\
\hline $50-59$ & 4 \\
\hline $60-69$ & 4 \\
\hline $70-79$ & 10 \\
\hline $80-89$ & 1 \\
\hline \multicolumn{2}{|l|}{ Gender } \\
\hline Female & 8 \\
\hline Male & 12 \\
\hline \multicolumn{2}{|l|}{ Ethnicity } \\
\hline British White & 19 \\
\hline Other & 1 \\
\hline \multicolumn{2}{|l|}{ Marital status } \\
\hline Single & 1 \\
\hline Married/civil partnership & 14 \\
\hline Widowed & 4 \\
\hline Divorced & 1 \\
\hline \multicolumn{2}{|l|}{ Carer } \\
\hline Spouse/partner & 14 \\
\hline Sibling & 1 \\
\hline Children & 5 \\
\hline \multicolumn{2}{|l|}{ Cancer site } \\
\hline Lung & 8 \\
\hline Upper gastrointestinal & 2 \\
\hline Lower gastrointestinal & 2 \\
\hline Genitourinary & 3 \\
\hline Other & 5 \\
\hline \multicolumn{2}{|l|}{ Stage of cancer } \\
\hline Advanced & 17 \\
\hline Early & 3 \\
\hline \multicolumn{2}{|l|}{ No. of admission/6 months } \\
\hline 1 admission & 7 \\
\hline 2 admissions & 5 \\
\hline 3 admissions & 6 \\
\hline 4 admissions & 2 \\
\hline Total & 43 \\
\hline
\end{tabular}


Table 2 Cause and process of admissions and common symptoms $(n=43)$

\begin{tabular}{|c|c|c|c|c|c|}
\hline Cause & $\mathbf{N}$ & Process & $\mathbf{N}$ & Symptom ${ }^{\text {a }}$ & $\mathbf{N}$ \\
\hline Chemotherapy & 30 & Direct to oncology ward & 35 & Fatigue & 12 \\
\hline Radiotherapy & 2 & Indirect to oncology ward via ED & 3 & Pain & 10 \\
\hline Immunotherapy & 3 & Indirect to other ward via ED & 5 & Diarrhoea & 9 \\
\hline Disease & 7 & & & Fever & 7 \\
\hline \multirow[t]{6}{*}{ Missed medication } & 1 & & & Nausea and vomiting & 5 \\
\hline & & & & Collapse & 5 \\
\hline & & & & Weight loss & 4 \\
\hline & & & & Anorexia & 4 \\
\hline & & & & Skin problems & 4 \\
\hline & & & & Breathlessness & 3 \\
\hline
\end{tabular}

a. many patients reported several symptoms 
Table 3 Participants' quotes

\begin{tabular}{|c|c|}
\hline No. & Quote \\
\hline Q1 & $\begin{array}{l}\text { They give me a lot of these diarrhoea tablets and codeines and all that to take and they said if you've got } \\
\text { diarrhoea take them, you know, up to eight a day of them and four of them a day, so I went two days to } \\
\text { see if it would work and they didn't you see, so and then I was back in again. (Patient, 70-79) }\end{array}$ \\
\hline Q2 & $\begin{array}{l}\text { I didn't know where I was, I, I couldn't do anything, nothing, just shut down and to be quite honest I } \\
\text { couldn't care, I didn't care whether I died or lived or what, that's how I felt. (Patient, 70-79) }\end{array}$ \\
\hline Q3 & $\begin{array}{l}\text { I go to [the cancer centre] about once a fortnight, well to be honest when they put me on the new drug I } \\
\text { was going once a week, did blood tests every week... we tend to go into the [cancer centre] for our } \\
\text { appointments just as a day, like they call it a day patient. (Patient, 50-59) }\end{array}$ \\
\hline Q4 & $\begin{array}{l}\text { We've got [the out-of-hours number] if, if anything serious happened, we can ring the [out-of-hours] } \\
\text { number, erm, we can ring the, the ward, the, the day, sort of day unit or we've got a [palliative care nurse } \\
\text { specialist] that we can ring at any time for him to speak to. (Wife of a patient [50-59]) }\end{array}$ \\
\hline Q5 & $\begin{array}{l}\text { When the, the mouth ulcers started I thought about taking Bonjela, you know, Bonjela from the chemist, } \\
\text { and I, and I thought well I'll ring them first to find out if it's alright to take Bonjela, and the guy on the } \\
\text { other end at [the out-of-hours number] said are you taking paracetamol? I said yeah, oh yeah, yeah. Ah, } \\
\text { you better come in straightaway then...I rang my daughter, she came and picked me up and we went into } \\
\text { [the cancer centre], then I was seen by a doctor, my blood was taken, the, and I, my neutrophils were low, } \\
\text { er, and then they, they prescribed the mouthwash and the, the gel, that was the only other time that I was } \\
\text { unplanned, I didn't [stay overnight]. (Patient, 70-79) }\end{array}$ \\
\hline Q6 & $\begin{array}{l}\text { She [the nurse on the phone] never hesitated when I rang up for him to go in, you know, there was none } \\
\text { of the, there isn't a bed or anything, there's always a bed available, so whatever time of day or night you } \\
\text { ring up they'll sort you out, they're very good, so. (Wife of a patient [70-79]) }\end{array}$ \\
\hline Q7 & $\begin{array}{l}\text { The only way it could have been avoided would be to not have the treatment... all the admissions I } \\
\text { would say wouldn't have been avoided because it was down to the treatment I was having, so it's like I } \\
\text { was always going to go in hospital anyway. (Patient, 40-49) }\end{array}$ \\
\hline Q8 & $\begin{array}{l}\text { It was a pleasure to actually go knowing the level of care that all the staff were giving her, erm. (Son of a } \\
\text { patient [70-79]) }\end{array}$ \\
\hline Q9 & $\begin{array}{l}\text { I mean when she got to [the cancer centre], being able to do these, her medication that she has at home, in } \\
\text { hospital, it's a lot easier, better for her to do that. (Husband of a patient [60-69]) }\end{array}$ \\
\hline Q10 & $\begin{array}{l}\text { I thought because we were going to [the cancer centre] to see Dr. [name removed] there was no point in } \\
\text { ringing our GPs up because they might have to do it through A\&E whereas if I went to [the cancer } \\
\text { centre] I know that, you know, it will be sorted there where he's a patient and he'd done his bloods and } \\
\text { his potassium. (Wife of a patient [60-69]) }\end{array}$ \\
\hline Q11 & $\begin{array}{l}\text { Well they'll do anything for you, anything, I don't think there was one, I could never complain, they was } \\
\text { always happy-go-lucky, they was always helping you. (Patient, 70-79) }\end{array}$ \\
\hline Q12 & $\begin{array}{l}\text { In [the cancer centre] it was, it was better for the fact that John could come at half past one in an } \\
\text { afternoon and stay 'til eight o'clock at night, you know, so there was that all afternoon. (Patient, 60-69) }\end{array}$ \\
\hline
\end{tabular}




\begin{tabular}{|l|l|}
\hline Q13 & $\begin{array}{l}\text { I'm finding it very hard at the moment, I've got a pacemaker. And, erm, I'm supposed to have a, another } \\
\text { operation which I've put off because of my husband, you know, erm. I'm very tired, you know, but, er, } \\
\text { (laughs) he wants to be at home.... I've got arthritis, I've had my large bowel removed, erm, (.) so, } \\
\text { (laughs) yes. (Wife of a patient [70-79]) }\end{array}$ \\
\hline Q14 & $\begin{array}{l}\text { I mean we've got, our eldest daughter's pregnant, she, she expects the baby in ten weeks time, nine, ten } \\
\text { weeks time, I've got David [their adopted son, 17 yr with developmental problems, behaving like a little } \\
\text { child, with autism, incontinence, who needs a lot of care] to consider, erm, I get [the adoption agency] in } \\
\text { a few times a week to come and look after him after school on a weekend, so that I can go see George } \\
\text { and then we do take David to see him but only once a week because he's quite noisy, erm, so you've just } \\
\text { got to, you've just got to grit your teeth and do it but it is hard, trying, I suppose it's hard trying to split } \\
\text { yourself into two people, to be in two places at once. (Wife of a patient [60-69]) }\end{array}$ \\
\hline Q15 & $\begin{array}{l}\text { The [community palliative care] nurse, she first came in in July when he had all this bruising to his leg } \\
\text { and just sort of more to introduce herself and say that she takes over care more when we finish the } \\
\text { chemotherapy while he's on the chemotherapy we come under the umbrella of [the cancer centre] and the } \\
\text { specialist nurses there. (Wife of a patient [60-69]) }\end{array}$ \\
\hline
\end{tabular}


Figure 1 Process of admissions

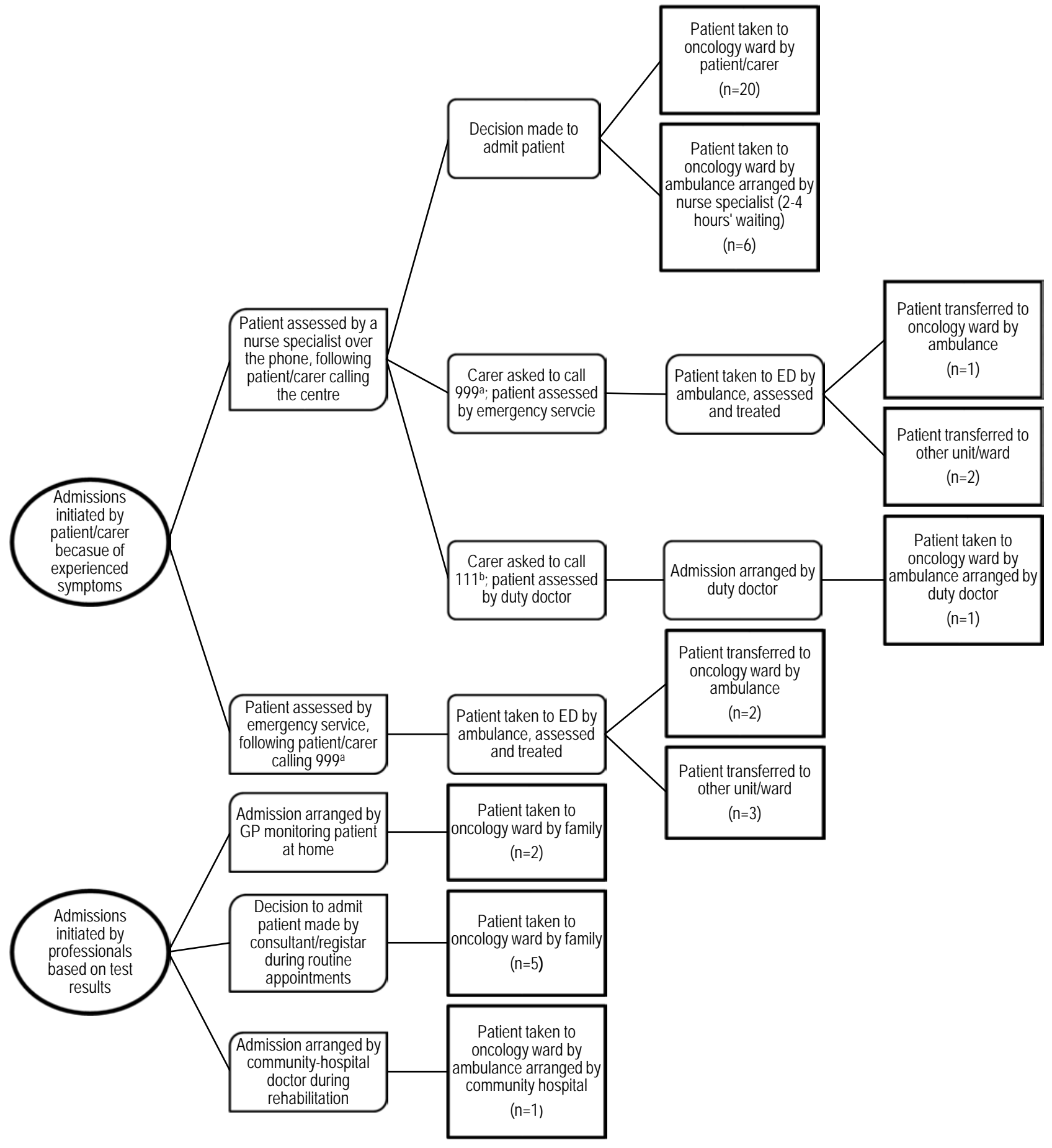

a. 999 - The main emergency number

b. 111 - The non-emergency medical number 